\section{Statistics don't count}

$\mathrm{T}$ here is a definite inadequacy in numbers, as my wife and I discovered recently during a 5week foray to Swaziland.

Jennifer is in third year medicine at the University of British Columbia and I am an ultrasound technician at Vancouver General Hospital. We thought we'd done the pre-trip research and compiled the requisite data that would prepare us for our stint as volunteers in a sub-Saharan hospital.

Swaziland is a landlocked country that is primarily surrounded by South Africa, but also bumps up against Mozambique, on the east coast of Africa. It is very small, but what it lacks in size it more than makes up for in destitution. It is one of the world's poorest countries, with unemployment at approximately $40 \%$, and an estimated $70 \%$ of the population living on less than US\$I per day.

In a country with more than I million people, there is no radiologist, no cardiologist, no neurosurgeon, no anesthesiologist, no pathologist and a surplus of other empty postings. Raleigh Fitkin Memorial Hospital has no hot water, nor is there running water in the operating theatre. There is no working defibrillator, no renal dialysis machine and more than once, surgery was cancelled due to a lack of sterile saline. The CD-4 count machine was broken.

But Swaziland's true hardship rears its ugly head in the form of HIV/AIDS.

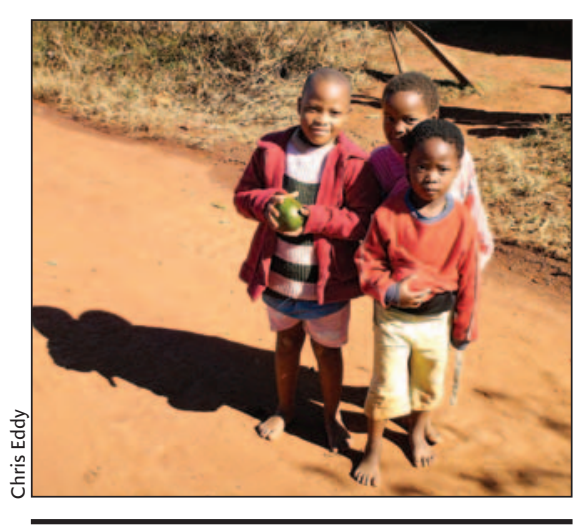

UNICEF anticipates that more than 10\% of Swaziland's population will be orphans by 2010, which translates into a staggering 120000 youngsters in one of the world's poorest nations.

The World Health Organization's official report on Swaziland has the infection rate at upwards of $40.4 \%$ of the adult populace ( $15-49$ years) as of 2003 . However, Swaziland's National Emergency Response Counsel for HIV/AIDS organization has recently released statistics indicating an infection rate of $42.6 \%$. The WHO's life expectancy statistics (2005) are abysmal: 38 for males, 37 for females. The US Central Intelligence Agency world fact book publishes even lower numbers (males: 31.8 years; females: 32.6 years) and pegs life expectancy as the world's lowest.

Last June, the Swaziland Vulnerability Committee, operating under the Ministry of Agriculture's National Disaster Relief Task Force, projected that life expectancy will drop to 30 years by
20I0. UNICEF anticipates there will be I20 000 orphans - more than 10\% of the entire population - by 2010.

Those are the statistics.

They don't count.

Certainly, they did not prepare us for the beautiful I6-year-old girl who came into emergency with a productive cough, and was dead 3 days later from extensively drug-resistant tuberculosis. They did not ready us for the mothers who arrived at the rural clinics, with their children in tow, and then rifled through their person for "passport-book" medical histories before requesting an HIV ARV treatment refill for their baby.

They could not brace us for the power outages in Emergency, or the shortfall of basic supplies.

When looking into the eyes of a dying child, numbers mean nothing. Chris Eddy RTR RDMS, Vancouver

DOI:I0.1503/cmaj.071364

CMAJ invites contributions to Dispatches from the medical front, in which physicians and other health care providers can provide eyewitness glimpses of medical frontiers, whether defined by location or intervention. The frequency of the section will be conditional on submissions, which must run a maximum 350 words or be subject to our ruthless editorial pencils. Forward submissions to: Wayne.Kondro@cma.ca

\section{News @ a glance}

Brief reprieve: The Vancouver-based InSite safe injection site has been given another 6-month reprieve from the federal Controlled Drugs and Substances Act. Health Minister Tony Clement said in a terse news release that the extension "will allow research on how supervised injection sites affect prevention, treatment and crime to be continued for another 6 months." Although scientific experts and health officials ar- gue that safe injection sites are demonstrably beneficial, Clement said earlier this year that the government believes the scientific evidence of their efficacy is entirely equivocal. The government has commissioned a study measuring such factors as "public order and safety issues," and "local contextual issues" (CMAJ 2007;176[13]:I813).

Haloperidol warning: The US Food and Drug Administration (FDA) has warned that injectable haloperidol should not be administered intravenously. Although the antipsychotic is to be used intramuscularly, it is sometimes used off-label as an intravenous injection to control agitation in critically ill patients. The FDA issued the warning after reviewing more than 2 dozen case reports of patients experiencing either sudden death or cardiac arrhythmias (including QT prolongation and torsades de pointes) after receiving intravenous injections of the drug. 